\title{
Boeremia exigua causing leaf spots on sweet potato in Brazil
}

\author{
A. Colmán ${ }^{1} \cdot$ I. M. Lima ${ }^{2} \cdot$ H. Costa $^{2} \cdot$ R. W. Barreto ${ }^{1}$ (I) \\ Received: 10 November 2019 / Accepted: 11 May 2020 / Published online: 16 May 2020 \\ (C) Australasian Plant Pathology Society Inc. 2020
}

\begin{abstract}
In what is a first for the world, leaf spot disease of sweet potato, caused by Boeremia exigua, is reported in Brazil. Identity of the fungus was confirmed by a combination of molecular and morphological data. Koch's postulates were fulfilled with a selected isolate of the fungus obtained from Santa Maria do Jetibá, state of Espírito Santo, Brazil.
\end{abstract}

Keywords Coelomycete asexual morph $\cdot$ Convolvulaceae $\cdot$ Leaf blight $\cdot$ Occurrence $\cdot$ Pycnidial fungus

Ipomoea batatas (Convolvulaceae) - sweet potato - is the sixth most important food crop worldwide (CIP 2020). Several diseases are limiting factors for this crop, including field and storage diseases (Clark et al. 2013). In Brazil, sweet potato has lost some of its former importance because of changes in the consumer's habits but still remains one of the top vegetables in Brazilian agriculture (Silva et al. 2008). These authors listed several fungal diseases that occur on sweet potato in Brazil, but considered that damage to the crop by fungal diseases is normally small.

In June 2015, sweet potato plants bearing severe leaf spot damage were observed in a plantation in the municipality of Santa Maria de Jetibá (state of Espirito Santo, Brazil). Lesions were initially circular but became irregular, slightly sunken and zonate, dark brown, surrounded by a chlorotic halo, coalescing and leading to a blight of part or entire leaves (Fig. 1a). Older lesions often became torn in their central parts. Numerous, black dots were repeatedly seen immersed in the necrosed tissues when viewed using magnifying lens.

Samples were dried in a plant press and taken to the laboratory for further examination. Fungal structures were mounted in lactoglycerol and lactofuchsin and slides were examined under an Olympus BX 51 light microscope equipped with DIC and fitted with an Olympus Q-COLOR3 camera. Images were captured with the software cellSens. Cultures were obtained by transfer of conidial masses from

R. W. Barreto

rbarreto@ufv.br

1 Departamento de Fitopatologia, Universidade Federal de Viçosa, Viçosa, Minas Gerais 36571-000, Brazil

2 Instituto Capixaba de Pesquisa, Assistência Técncia e Extensão Rural, Venda Nova do Imigrante, ES 29374-000, Brazil sporulating bodies onto potato dextrose-agar (PDA) plates with a sterile fine pointed needle. After such spore masses became humid and soft, conidia were spread over the surface of the medium with a loop. The surface of the medium was then examined under the high power of a dissecting microscope (Olympus SZX7) and areas where conidia were found to be sparse were selected and single conidia were transferred to fresh PDA plates. A representative culture was deposited in the culture collection of the Universidade Federal de Viçosa (COAD 2711). A dried herbarium sample was deposited in the local herbarium (VIC42998).

The following morphology was observed for the fungus based on observation of structures formed on PDA: Pycnidia globose to subglobose, 60 to $280 \mu \mathrm{m}$ diam, non-papillate, immerse; conidiogenous cells flask-shaped, $45 \times 2.54 \mu \mathrm{m}$; conidia, ellipsoid to oblong, $57 \times 23 \mu \mathrm{m}$, mainly aseptate, but occasionally 1-septate, hyaline, smooth (Figs 1b, c).

DNA from a single-spore pure culture was extracted using Wizard Genomic DNA Purification Kit (Promega), according to the manufacturer's instructions. The internal transcribed spacer (ITS) and two other loci [(LSU, and $\beta$-tubulin (tub2), regions] were amplified and sequenced as described by Chen et al. (2015) using the pair primers ITS4/ITS5 (for ITS), LR0R/ LR5 (for LSU) and Btub2Fd and Btub4Rd (for tub2). Sequences were generated and deposited in GenBank under de accession numbers MK836423, MK850241 and MN909292. The BLAST analyses of the LSU, ITS and tub2 sequences yielded $100 \%, 99.8 \%$ and $99.5 \%$ homology with sequences of the type species of $B$. exigua var. exigua available in GenBank - respectively EU754183, FJ427001 and FJ427112.

Based on the combination of morphological and molecular data, it was concluded that the fungus found on leaf spots of sweet potato was $B$. exigua. The identification of $B$. exigua 
Fig. 1 Boeremia exigua on Ipomoea batatas. a Leaf spot symptoms and blight on mature sweet potato leaf; b Group of conidiogenous cells bearing immature conidia; c. Mature conidia; d. Results of pathogenicity test on sweet potato plants six days after inoculation Scale bars $=20 \mu \mathrm{m}$

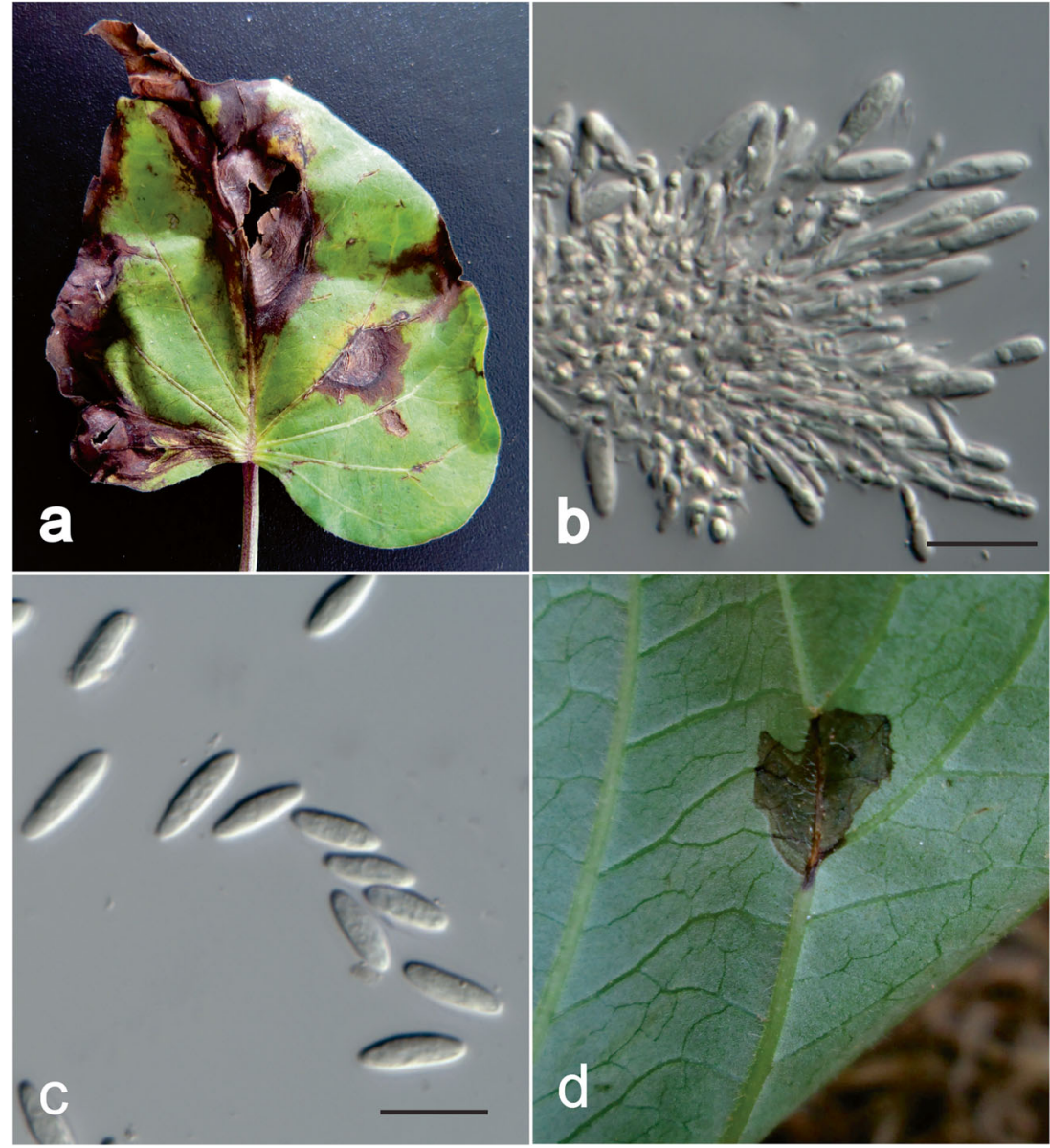

varieties is mainly linked to host associations (Aveskamp et al. 2009). Our phylogenetic analyses suggested that B. exigua causing leaf spot in sweet potato may represent a new variety, to be proposed in later studies.

Pathogenicity of COAD 2711 was tested. Four healthy plants were inoculated with a $1 \times 10^{6}$ conidia/ml conidial suspension until runoff whereas two controls were sprayed with sterile water alone. After inoculation, plants were maintained for $48 \mathrm{~h}$ in a dew chamber and then transferred to a greenhouse bench with temperature ranging between 22 and $26^{\circ} \mathrm{C}$. After six days, leaf spot symptoms equivalent to those observed in the field were observed. Controls remained healthy. Pure cultures producing pycnidia and conidia with the same morphology as described above for COAD 2711 were obtained from diseased leaves (Fig. 1d).

Boeremia exigua has been reported on various plants worldwide, but mostly in connection to rots of various organs, and particularly associated with post-harvest diseases (Farr and Rossman 2019). There is a recent record of this fungus causing post-harvest disease of sweet potato in China (Gai et al. 2016) but this is the first report of B. exigua causing leaf spots on sweet potato in Brazil and from the world.

\section{References}

Aveskamp MM, Woudenberg JHC, de Gruyter J, Turco E, Groenewald JZ, Crous PW (2009) Development of taxon-specific sequence characterized amplified region (SCAR) markers based on actin sequences and DNA amplification fingerprinting (DAF): a case study in the Phoma exigua species complex. Mol Plant Pathol 10:403-414

Chen Q, Jiang JR, Zhang GZ, Cai L, Crous PW (2015) Resolving the Phoma enigma. Stud Mycol 82:137-217

CIP International Potato Center (2020) Sweetpatato facts and figures. https://cipotatoorg/sweetpotato/sweetpotato-facts-and-figures/. Accessed 1 Feb 2020

Clark CA, Ferrin DM, Smith TP, Holmes GJ (2013) Compendium of sweetpotato diseases, pests, and disorders. APS Press, St. Paul

Farr DF, Rossman AY (2019) Systematic mycology and microbiology laboratory, ARS, USDA http://ntars-gringov/fungaldatabases/. Accessed 20 Mar 2019

Gai YP, Ma HJ, Chen XL, Chen HH, Li HY (2016) Boeremia tuber rot of sweet potato caused by $B$. exigua, a new postharvest storage disease in China. Can J Plant Pathol. https://doi.org/10.1080/07060661. 2016.1158742

Silva JBC, Lopes CA, Magalhães JS (2008) Como plantar batata-doce. https:/www.embrapa.br/web/portal/hortalicas/como-plantar-batatadoce. Accessed 30 Mar 2019 